\title{
A widely tunable, near-infrared laser-based trace gas sensor for hydrogen cyanide (HCN) detection in exhaled breath
}

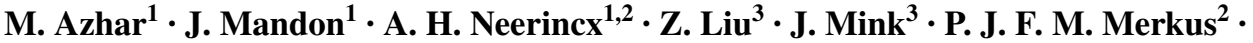 \\ S. M. Cristescu ${ }^{1}$ F. J. M. Harren ${ }^{1}$
}

Received: 24 March 2017 / Accepted: 3 October 2017 / Published online: 24 October 2017

(c) The Author(s) 2017. This article is an open access publication

\begin{abstract}
A compact, cost-effective sensor is developed for detection of hydrogen cyanide (HCN) in exhaled breath within seconds. For this, an off-axis integrated cavity output spectroscopy setup is combined with a widely tunable compact near-infrared laser (tunability 1527-1564 nm). For $\mathrm{HCN}$ a detection sensitivity has been obtained of $8 \mathrm{ppbv}$ in nitrogen (within $1 \mathrm{~s}$ ), equal to a noise equivalent absorption sensitivity of $1.9 \times 10^{-9} \mathrm{~cm}^{-1} \mathrm{~Hz}^{-1 / 2}$. With this sensor we demonstrated the presence of $\mathrm{HCN}$ in exhaled breath; its detection could be a good indicator for bacterial lung infection. Due to its compact, cost-effective and user-friendly design, this laser-based sensor has the potential to be implemented in future clinical applications.
\end{abstract}

\section{Introduction}

Trace gas sensing has become a highly valuable tool for applications such as atmospheric research [1,2], industrial processes [3], agriculture emissions [4, 5] and biomedical diagnostics [6-8]. Laser spectroscopy offers advantages for trace gas detection, in particular in speed, specificity, sensitivity and real-time detection. Laser-based spectroscopic methods have been widely used for sensing, such as laserinduced breakdown spectroscopy (LIBS) [9], cavity ring

F. J. M. Harren

F.Harren@science.ru.nl

1 Trace Gas Research Group, Molecular and Laser Physics, IMM, Radboud University, Nijmegen, The Netherlands

2 Department of Paediatrics, Amalia Children's Hospital, University Medical Centre Nijmegen, Nijmegen, The Netherlands

3 VTEC Lasers and Sensors, Eindhoven, The Netherlands down spectroscopy, wavelength modulation spectroscopy, off-axis integrated cavity output spectroscopy (OA-ICOS) $[10,11]$ and photoacoustic spectroscopy $[12,13]$. For these spectroscopic methods specificity, costs and complexity depend highly on the used laser wavelength. For probing molecular gas species in mid-infrared molecular fingerprint region $(2-20 \mu \mathrm{m})$ continuous wave quantum cascade lasers (QCL) [14] and interband cascade lasers [15] are mostly used, next to non-linear generated light via different frequency generation (DFG) [16], or optical parametric oscillators (OPO) [17].

In the near-infrared wavelength region, compact diode lasers are designed to operate efficiently around the $1.5 \mu \mathrm{m}$ wavelength region for telecommunications purposes, as optical losses in fibers are minimal at this wavelength. In recent years, an advance and sensitive optical spectrometer based on a near-infrared laser and cavity ring down spectroscopy (CRDS) has been successfully developed and used to measure $\mathrm{HCN}$ below the ppbv (part per billion volume, $\left.1: 10^{9}\right)$ level $[18,19]$. In the present study, a widely tunable telecommunication laser is used in combination with off-axis integrated cavity output spectroscopy (OA-ICOS) for trace gas detection. Off-axis-ICOS offers a compact, robust setup with fast detection and lower costs, but at similar sensitivity performance levels as compared to CRDS. As such, these features allow this to be considered as an easy-to-implement solution for real-world applications.

Here, we will use the system for detection of $\mathrm{HCN}$ in exhaled breath. In vitro studies have shown that cultures of Pseudomonas aeruginosa bacteria produce the toxic hydrogen cyanide (HCN) [20, 21]. Furthermore, HCN has been detected in sputum of $P$. aeruginosa infected cystic fibrosis (CF) patients [22, 23]. In vivo studies using selected ion flow tube mass spectrometry (SIFT-MS) report that HCN can be identified as a biomarker for $P$. aeruginosa infection 
in exhaled breath of CF patients [24-27]. Cystic fibrosis itself is an inherited genetic disease, which is characterized by recurrent pulmonary infections and chronic lung inflammation. P. aeruginosa is one of the most common pathogens causing these respiratory infections and is associated with a high morbidity and mortality [28]. It can be successfully eradicated when the condition is detected early [29]. Current detection methods are sputum culture, bronchoscopy, cough swab or chest X-ray. Unfortunately, these methods are far from ideal since they are invasive, not reliable, or samples are difficult to obtain [22,30,31]. Therefore, there is a vital need for a non-invasive, reliable, easy to use alternative method to diagnose $P$. aeruginosa infection in an early stage. Previously, we have monitored $\mathrm{HCN}$ production levels in vitro from P. aeruginosa and Staphylococcus aureus bacteria, cultured in laboratory environments [27, 32, 33]. In addition, we have detected $\mathrm{HCN}$ in exhaled breath $S$. aureus infected CF patients. The system was using PhotoAcoustic (PA) spectroscopy with a cw optical parametric oscillator (OPO) operating in the 3-4 $\mu \mathrm{m}$ wavelength region (referred to as OPO-PA elsewhere in this paper). Although sensitive, the laser has high operational costs, is complex to operate and bulky. Here, we aim to develop a compact, cost-effective sensor for detecting $\mathrm{HCN}$ in exhaled breath in real-time.

\section{Experimental setup}

The experimental setup is depicted in Fig. 1. The laser was a fiber-coupled near-infrared digital supermode distributed Bragg reflector (DS-DBR) laser (VTEC Lasers and Sensors Ltd, Eindhoven, The Netherlands). The continuous wave (cw) laser operated in the C-band window, covering a wavelength region between $1527-1564 \mathrm{~nm}\left(6393.9-6548.8 \mathrm{~cm}^{-1}\right.$, see also Fig. 5) via 89 integrated channels. Tuning the current parameters, the laser was able to tune over a wide wavelength range and sweep within the mode-hop-free regions, enabling detection of multispecies gases. The channels are distributed evenly over the range and the tuning range of each channel is about $0.4 \mathrm{~nm}\left(\sim 1.6 \mathrm{~cm}^{-1}\right)$, ensuring theoretically a full spectral coverage. Practically, for most of the channels, the covering range was as expected; however, the mode-hope-free region was limited to a range varying from 0.1 to $0.25 \mathrm{~nm}\left(\sim 0.5\right.$ to $\left.1 \mathrm{~cm}^{-1}\right)$. The laser wavelength was crosschecked with a wavelength meter (model TQ 8325, Advantest, Japan).

The laser was pointed towards an optical absorption cell operated in an OA-ICOS configuration, the cell was modified as compared to earlier investigations [34]. Here, the cell consisted of two highly reflective mirrors (99.8\% reflectivity at $1500 \mathrm{~nm}$ (Layertec, Germany) resulting in an effective path length of 300 meters and a cavity finesse of 1570 . The cell was $30 \mathrm{~cm}$ long with a $20 \mathrm{~mm}$ inner diameter and was made of polymer (Rulon 641). In general, $\mathrm{HCN}$ adsorbs to metal surfaces that can compromise the response time and accuracy of the setup when measuring at ppbv concentration levels. As such, care was taken not to have metal contact surfaces up to the outlet of the detection cell. The inlet of the cell consisted of Teflon tubing and a Teflon gas valve (Polyfluor Plastics, Oosterhout, The Netherlands). The outlet of the cell went via a mass flow controller (Brooks Instrument, Veenendaal, The Netherlands) towards a vacuum pump. This mass flow controller in combination with the inlet gas valve was adjusted to maintain the pressure in the gas cell at 120 mbar (measured by a digital pressure meter). The mass flow controller and vacuum pump worked in unison to provide a constant gas flow (approx. $11 \mathrm{~h}^{-1}$ ) through the cell. The light behind the cell is collected with a lens (focal length $25.4 \mathrm{~mm}$ ) and detected by a photodetector (LCA-S400K-IN-FS from Femto Messtechnik, Germany), with a gain of $10^{7} \mathrm{~V} \mathrm{~A}^{-1}$. The photodetector signal is collected on an ADC card and analyzed with a LabVIEW program. The polymer cell, lens and photodetector are kept in a temperature-controlled enclosure (not shown) at $25^{\circ} \mathrm{C}$. The temperature in this enclosure is stabilized by heating resistors and a temperature controller.

Since water vapor and carbon dioxide are important constituents of breath, care was taken to choose a $\mathrm{HCN}$ spectral line with minimum overlap to $\mathrm{H}_{2} \mathrm{O}$ - and $\mathrm{CO}_{2}$-absorption lines. The laser was operated at $1538.17 \mathrm{~nm}\left(6501.24 \mathrm{~cm}^{-1}\right)$, and scanned over the HCN absorption line $\left[2 \nu_{1}\right.$ (P6) transition] at a modulation frequency of $50 \mathrm{kHz}$. At this wavelength, the laser delivered an output power of $20 \mathrm{~mW}$. The power received on the detector was at most $1 \mathrm{~mW}$. The
Fig. 1 Setup showing the fiber-coupled DS-DBR laser, the polymer gas cell in an offaxis configuration, with highly reflective mirrors $(99.8 \%$ reflectivity at $1500 \mathrm{~nm}$ ), lens and photodetector (PD). Gas to be analyzed is introduced via the gas inlet. A mass flow controller and vacuum pump regulate the pressure and gas flow in the cell

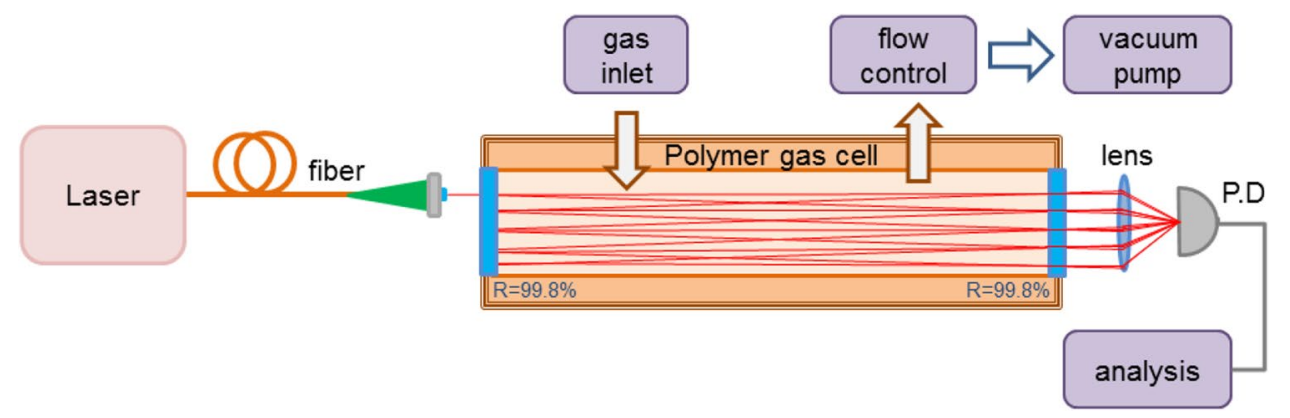


system was calibrated by obtaining the photodetector signal with the cell filled with pure nitrogen $\left(\mathrm{N}_{2}\right)$ and then subsequently filled with a certified, calibrated mixture of 5 ppmv $\mathrm{HCN}$ in $\mathrm{N}_{2}$ (Linde gas, The Netherlands). A differential signal obtained from the $\mathrm{HCN}$ signal and the pure $\mathrm{N}_{2}$ signal provides a reference scan to which unknown concentrations of $\mathrm{HCN}$ can be compared. During the measurements of unknown concentration of $\mathrm{HCN}$, the signal consists of multiple scans averaged over $1 \mathrm{~s}$ on the ADC. An HCN concentration is retrieved by a curve-fitting of the recorded scan to the reference scan. As such, the HCN concentrations are less sensitive to laser power fluctuations or wavelength drifts than by measuring the absorption peak values. The Allan Variance [35] resulting from these signals is shown in Fig. 2; it provides a statistical estimate of the stability and detection limit of the system over various acquisition times. The signal (red line, Fig. 2) is compared with the dark current of the photodetector (blue line) and previously obtained experimental result (green line) described earlier [34]. To retrieve the HCN concentration, the signals from the samples were averaged over $10 \mathrm{~s}$ resulting in a detection limit of 2-3 ppbv. The remaining limiting factors of the sensor are due to a limited absorption path length at short time scale $(<1 \mathrm{~s})$, and wavelength instability of the laser source at longer time scale $(>10 \mathrm{~s})$.

The current system is an improved version of a previously reported setup [34]. At that time, a detection limit was reported of $\sim 80 \mathrm{ppbv}$ at $1 \mathrm{~s}$ acquisition time; this was sufficient for in vitro concentration measurements from bacteria (up to 2 ppmv of $\mathrm{HCN}$ ). However, to measure $\mathrm{HCN}$ concentrations in human breath (1-100 ppbv) [24], the

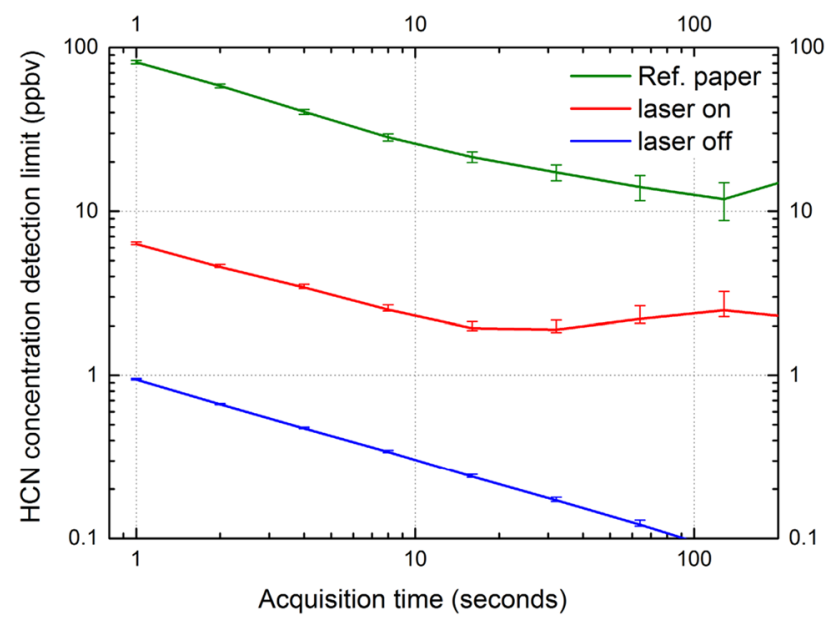

Fig. 2 Allan variance of the hydrogen cyanide (HCN) concentration detection limits for various acquisition times. The detection limits in reference paper [34] (green) and the improved detection limit of the current off-axis integrated cavity output spectroscopy (OA-ICOS) setup (red) reported here. The lowest detection limit possible with the used detector and acquisition electronics is shown in blue detection sensitivity of the system and the time response of the cell needed to be improved. This was achieved by changing to a stronger absorption line for $\mathrm{HCN}$ and redesigning the setup. The modifications include a different gas cell to avoid HCN adsorption, a more sensitive type of photodetector and an improved light collection optics. With these changes the optical signal on the detector was found to be substantially higher and electronic amplification could be excluded. All optical components were installed on translation stages for precise alignment. The fiber in-coupling setup, as was reported earlier, was decoupled from the cell, thereby increasing the flexibility of the input beam launchangle into the cavity. As explained before, the setup was also placed in a temperature-controlled, thermally insulated enclosure to improve long-term stability.

By removing metal components in the inlet system and from the cell, HCN adsorption could be reduced significantly. The polymer absorption cell and polymer tubing and fitting leading to the inlet of the cell increased the reliability of HCN detection at low ppbv levels. The mass flow controller, which was an unavoidable metal component, was installed in the output of the system prior to the vacuum pump, thereby maintaining the integrity of the detection measurements.

\subsection{Breath sampling}

Breath was collected, in triplicate, from $10 \mathrm{CF}$ patients (> 5 years old); in total 29 breath samples were analyzed. Patients were recruited from the outpatient clinic of Radboud University Medical Center Nijmegen, and Erasmus Medical Center Rotterdam, The Netherlands. After the patients rinsed their mouth with water, two single mouth-exhaled breath samples were collected, using a commercially available breath sampler (Loccioni, Angeli di Rosora, Italy), at a constant flow rate of $300 \mathrm{ml} \mathrm{s}^{-1}$. Briefly, the collection line consisted of a bacterial filter (Air Safety Limited, Lancashire, UK), a non-rebreathable T-piece (Vacumed, Ventura, USA), a $\mathrm{CO}_{2}$ sensor, and a calibrated buffer pipe (Loccioni, Angeli di Rosora, Italy). This pipe was connected to a Teflon T-piece which split the line towards a $150 \mathrm{ml}$ Tedlar discard bag for the collection of the exhaled breath from the upper trachea (i.e. dead space) and towards a 31 Tedlar bag (ProCare B.V., Groningen, The Netherlands). The latter was used for analyzing the breath sample. Two bags filled with breath (filling time separated by $90 \mathrm{~s}$ ) from the same subject were collected and stored for maximum $8 \mathrm{~h}$ prior to analysis. This study was approved by the local medical ethics committee (CMO - Nijmegen/Arnhem) which waived written informed consent. Oral consent was obtained from participants aged 12 years and older, and parents of children aged 6-18 years. 


\section{Results}

The HCN measurements of the OA-ICOS setup reported here are compared to the optical parametric oscillator-based photoacoustic (OPO-PA) setup as described earlier [33]. Initially, $\mathrm{HCN}$ mixtures with a variety of concentrations were made in the sampling bags, diluting the calibrated mixture of 5 ppmv $\mathrm{HCN}$ in $\mathrm{N}_{2}$ with pure $\mathrm{N}_{2}$ gas using mass flow controllers. In between measuring the bags, the gas cell in the system is flowed with pure $\mathrm{N}_{2}$ to obtain a zero gas reading. The zero gas reading is subtracted from the mean value when the HCN mixture is in the cell, once the measured value stabilizes. Excellent correlation (calculated Pearson's $r=0.999$ ) is observed between the measurements of these bags measured with both systems (OPO-PA and OA-ICOS), as seen in Fig. 3a. In Fig. 3b the OA-ICOS system readout is seen. It demonstrates the ventilation response of the cell, as the HCN concentration rises from zero to a stable concentration in about $50 \mathrm{~s}$ ( $40 \mathrm{~s}$ for an inert gas).

After this, exhaled breath samples were analyzed on the same day of collection (within $8 \mathrm{~h}$ ) with both the OA-ICOS setup and the Optical Parametric Oscillator-based photoacoustic (OPO-PA) setup. The OA-ICOS readings were taken after the OPO-PA readings (time difference of $<1 \mathrm{~h}$ ). Each bag was analyzed for 10-15 min by controlled deflation of the bag's constituents into the setup. Figure 4 gives the HCN concentration results obtained by the OPO-PA and the OA-ICOS for the 29 breath samples. Figure 4a shows a Bland-Altman plot comparing the two systems. The OPOPA system measurements show a higher mean $\mathrm{HCN}$ concentration of around $\sim 23 \mathrm{ppbv}$ in comparison to the OA-ICOS setup. An acceptable degree of correlation was inferred on comparing the two systems (calculated Pearson's $r=0.898$ ). The systematic deviation in the two systems could be attributed to the overlapping spectra in the near-infrared wavelength region of $\mathrm{HCN}$ and $\mathrm{CO}_{2}$ at lower $(<50 \mathrm{ppbv})$ concentrations of $\mathrm{HCN}$. Figure $4 \mathrm{~b}$ shows that, although the spectral lines of $\mathrm{HCN}\left(6501.23 \mathrm{~cm}^{-1}\right)$ and $\mathrm{CO}_{2}\left(6501.51 \mathrm{~cm}^{-1}\right)$ are separated, for high concentrations of $\mathrm{CO}_{2}$ the wings of the $\mathrm{CO}_{2}$ line are influencing the background levels of the $\mathrm{HCN}$ line. For Fig. $4 \mathrm{~b}$ we used for the calculation a mixture of 5\% $\mathrm{CO}_{2}, 0.1 \%$ water and $50 \mathrm{ppbv}$ of $\mathrm{HCN}$. In the results shown in Fig. $3 \mathrm{a} \mathrm{CO}_{2}$ was absent, since this contained only $\mathrm{HCN}$ and $\mathrm{N}_{2}$. With a typical value $0-50$ ppbv of $\mathrm{HCN}$ in human breath, the residual background from $\mathrm{CO}_{2}$ in the spectrum will affect the measurements, leading to a lower mean value with the OA-ICOS setup as compared to the OPO-PA results. Taking into account the absorption of $\mathrm{CO}_{2}$ within the scanning range, the $\mathrm{CO}_{2}$ concentration can be estimated and the recorded data corrected. For this, a mixture of 5\% $\mathrm{CO}_{2}$ was measured and used as a second reference for the data measurements. Therefore, the signal coming from the unknown sample was fitted as a linear combination of the two reference scans $\left(\mathrm{HCN}\right.$ and $\left.\mathrm{CO}_{2}\right)$. The corrected results as shown in Fig. 4c.

\section{Discussion}

Here, we evaluated the performance of the near-infrared laser-based sensor for the detection of $\mathrm{HCN}$ at ppbv level in exhaled breath of CF patients. The laser was used in combination with OA-ICOS and was able to detect $\mathrm{HCN}$ in $\mathrm{N}_{2}$ down to $8 \mathrm{ppbv}$ in $1 \mathrm{~s}$. The OA-ICOS setup offers advantages over the mid-infrared OPO with photoacoustic detection, mainly due to the simpler and cost-effective laser system used. The near-infrared fiber coupled laser needs no sensitive alignment as compared to the OPO system; the latter is more bulky and needs frequent maintenance. Although the line strengths of $\mathrm{HCN}$ in the mid infrared $(3 \mu \mathrm{m})$ wavelength are about $100 \times$ stronger as at $1.5 \mu \mathrm{m}$ [36], the near-infrared OA-ICOS setup is able to provide comparable detection sensitivities [32]. Another important aspect is the fast response of OA-ICOS setup (s), in comparison with photoacoustic detection, which can take a few minutes for a single measurement. The latter is due to the slow scanning over the absorption line generating the photoacoustic response. The volume refresh time of the OA-ICOS was improved down to $50 \mathrm{~s}$ for $\mathrm{HCN}$ by avoiding any metal components in the gas handling system until the outlet of the gas cell. For an
Fig. 3 a Comparison of hydrogen cyanide (HCN) concentrations measured by the optical parametric oscillator-based photoacoustic (OPO-PA) setup and off-axis integrated cavity output spectroscopy (OA-ICOS), measuring $\mathrm{HCN}$ mixtures in nitrogen $\left(\mathrm{N}_{2}\right)$. b HCN concentration readout of the ICOS setup versus acquisition time of the sample mixtures in a
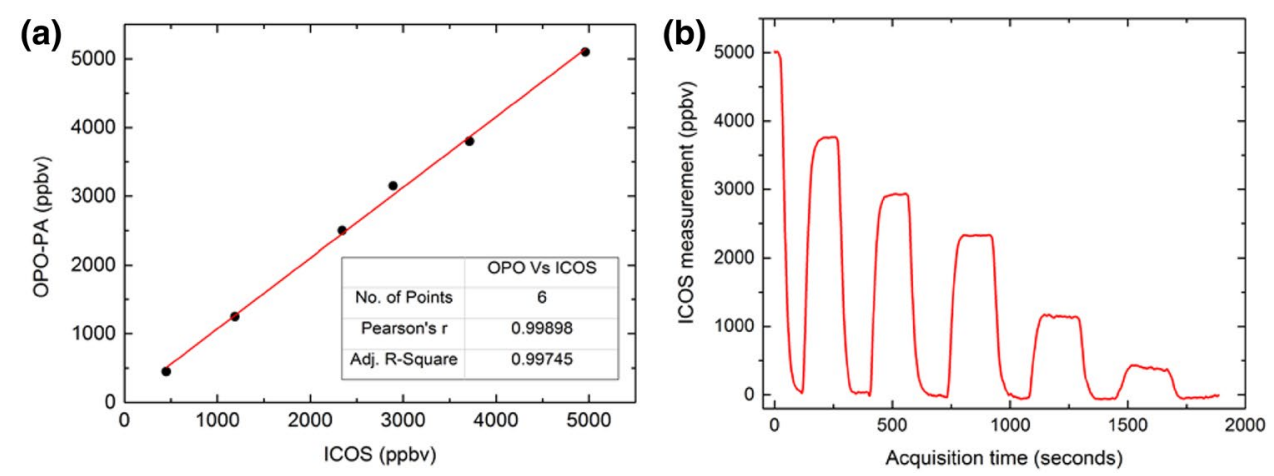


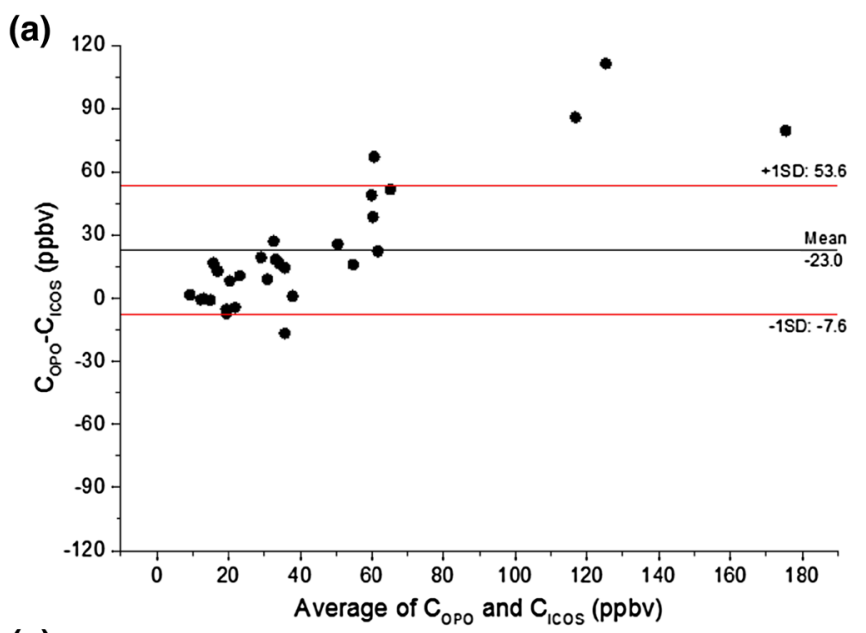

(c)

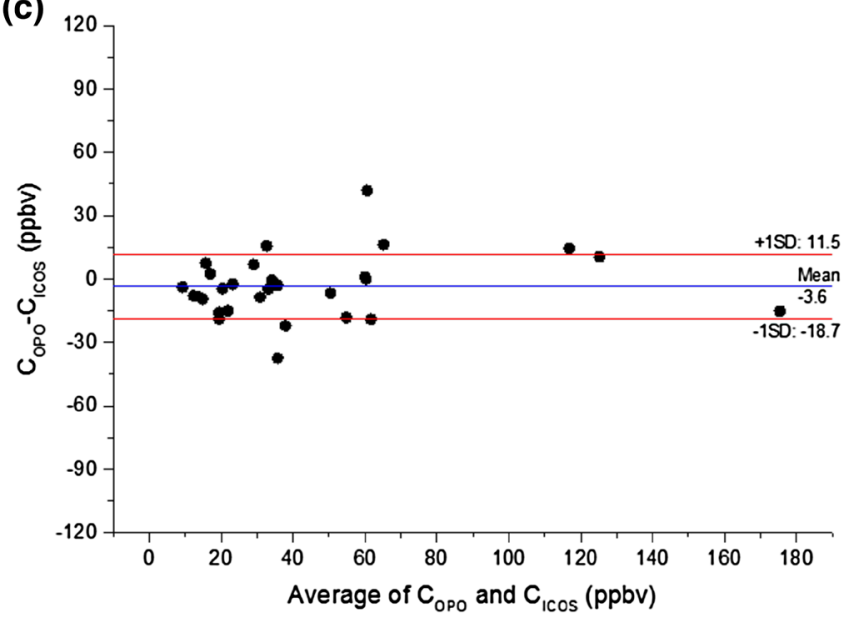

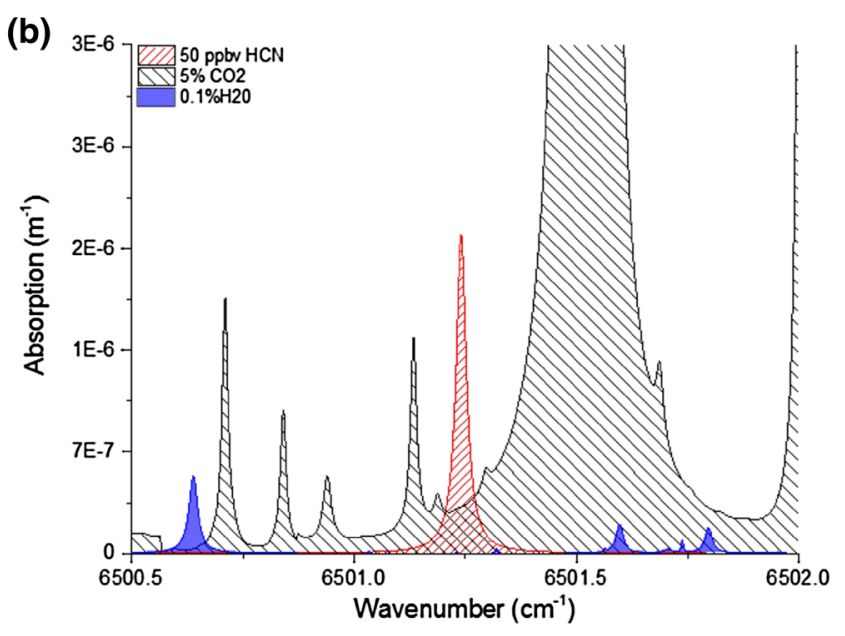

Fig. $4 \mathrm{HCN}$ concentrations measured by the OPO-PA $\left(C_{\mathrm{OPO}}\right)$ and OA-ICOS $\left(C_{\mathrm{ICOS}}\right)$, while measuring 29 breath samples from patients. a A Bland-Altman plot comparing the two systems show a higher mean value ( $23 \mathrm{ppbv})$ of the OPO-PA system. b Calculated spectra of $0.1 \% \mathrm{H}_{2} \mathrm{O}, 5 \% \mathrm{CO}_{2}$ and $50 \mathrm{ppb}$ of $\mathrm{HCN}$ show an overlap in spectral

inert gas, the volume refresh time was $40 \mathrm{~s}$. A faster refresh time using wider gas tubing diameters would help to reach a refresh time of a few seconds, needed for online breath analysis.

More generally, spectrometers based on a near-infrared laser and a high finesse cavity are offering interesting feature to assess low HCN concentration. Since early 2010, a reported spectrometer based on CRDS demonstrated a detection limit as low as 300 pptv with few minutes acquisition time [18]. In this work, at the cost of a lower sensitivity reaching the ppbv level, the choice of ICOS offers a more robust setup to the environment and fast time measurements, paving the way of optical spectrometer technology towards commercial products.

In the near-infrared wavelength region, the HCN absorption line overlaps with a weak $\mathrm{CO}_{2}$ absorption line. To correct for this it is sufficient to recording first the absorption lines of $\mathrm{CO}_{2}$ and $\mathrm{HCN}$ in that wavelength region [36], which causes the deviation between the OPO-PA and OA-ICOS measurements, while measuring breath. $\mathbf{c}$ A Bland-Altman plot after correction of the OA-ICOS concentrations by $\mathrm{CO}_{2}$

when only $\mathrm{CO}_{2}$ is present in the cell. After that, when both $\mathrm{HCN}$ and $\mathrm{CO}_{2}$ are in the cell from the breath sample, the $\mathrm{HCN}$ concentration can be properly determined.

The used telecom laser is portable, compact and easy to use. The laser is designed to work in the telecom C-band window covering the wavelength region $1527-1564 \mathrm{~nm}$ (6394-6549 $\mathrm{cm}^{-1}$ ) via 89 integrated channels. These channels correspond to particular wavelengths in this region and are selected by a software program provided by the manufacturer. Multiple channels can be selected and swept in sequence order to access multispecies gas spectral regions. When the switching between multiple channels is synchronized with detection and acquisition electronics, multiple gases can be measured by the same system. To emphasize this, Fig. 5 shows the calculated spectra of various gases in this wavelength region for a concentration of $50 \mathrm{ppbv}$ and a path length of $300 \mathrm{~m}$. 


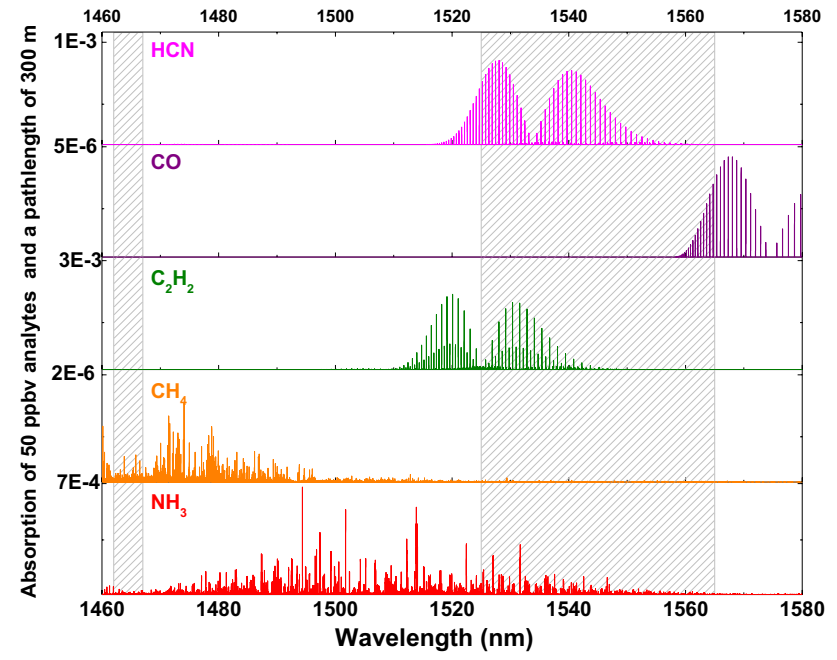

Fig. 5 Calculated spectra of molecules in the neighborhood of the laser operating wavelengths [36]. The absorption is calculated at a pressure of 120 mbar for a concentration of 50 ppbv and the absorption path length of $300 \mathrm{~m}$. The shaded areas indicate the mode-hopfree operating wavelength regions of the laser

\section{Conclusion}

A compact, cost-effective, infrared laser-based sensor is developed for detecting hydrogen cyanide (HCN) in exhaled breath within seconds. The widely tunable laser (tunability $1527-1564 \mathrm{~nm}$ ) is used in combination with an off-axis integrated cavity output spectroscopy (OA-ICOS). The system is able to detect $\mathrm{HCN}$ in $\mathrm{N}_{2}$ down to 8 ppbv in $1 \mathrm{~s}$, equal to a noise equivalent absorption sensitivity (NEAS) of $1.9 \times 10^{-9} \mathrm{~cm}^{-1} \mathrm{~Hz}^{-1 / 2}$. The response of the system is mainly determined by the ventilation time. This can be reduced to a single second by increasing the pump capacity and shortening gas tubing with larger diameter towards the pump without any consequence for the sensitivity of the system [11]. With this sensor we were able to demonstrate the presence of $\mathrm{HCN}$ in exhaled breath of $\mathrm{CF}$ patients. The sensor system offers several advantages, such as ease of use, and cost efficiency. The proposed method of monitoring breath from patients is non-invasive and patient-friendly, requiring the patient only to breathe into a sample bag.

The compactness of the system makes installing of the entire telecom-based OA-ICOS system a realistic prospect for online sampling. The capability for multispecies trace gas detection makes this spectrometer useful for a variety of industrial, atmospheric, environmental and biological/medical gas sensing applications. Measuring $\mathrm{HCN}$ in exhaled breath in real-time could result in more accurate, quantitative $\mathrm{HCN}$ concentration readings and avoid discrepancies arising from storage of the breath in bags for hours. Current biomedical studies along this line are being pursued.
Acknowledgements This work was supported by the GO-EFRO Ultragas, Project no. 2009-010034 of province of Gelderland (The Netherlands) and EU, IOP-Photonics, Project no. IPD100025 and Longfonds (The Netherlands), Project no. 3.3.11.002. Authors would like to thank Microbiology Department at Radboud University Medical Center (Nijmegen, The Netherlands) and the Erasmus Medical Center (Rotterdam, The Netherlands) for providing breath samples of volunteers. We also would like to thank Ylona Linders, Laura Vermeulen and Vera Tiemes helping in collecting and transporting the breath samples.

Open Access This article is distributed under the terms of the Creative Commons Attribution 4.0 International License (http://creativecommons.org/licenses/by/4.0/), which permits unrestricted use, distribution, and reproduction in any medium, provided you give appropriate credit to the original author(s) and the source, provide a link to the Creative Commons license, and indicate if changes were made.

\section{References}

1. A. Guenther, C.N. Hewitt, D. Erickson, R. Fall, C. Geron, T. Graedel, P. Harley, L. Klinger, M. Lerdau, W.A. McKay, T. Pierce, B. Scholes, R. Steinbrecher, R. Tallamraju, J. Taylor, P. Zimmerman, J. Geophys. Res. Atmos. 100(D5), 8873-8892 (1995)

2. T.B. Ryerson, A.E. Andrews, W.M. Angevine, T.S. Bates, C.A. Brock, B. Cairns, R.C. Cohen, O.R. Cooper, J.A. de Gouw, F.C. Fehsenfeld, R.A. Ferrare, M.L. Fischer, R.C. Flagan, A.H. Goldstein, J.W. Hair, R.M. Hardesty, C.A. Hostetler, J.L. Jimenez, A.O. Langford, E. McCauley, S.A. McKeen, L.T. Molina, A. Nenes, S.J. Oltmans, D.D. Parrish, J.R. Pederson, R.B. Pierce, K. Prather, P.K. Quinn, J.H. Seinfeld, C.J. Senff, A. Sorooshian, J. Stutz, J.D. Surratt, M. Trainer, R. Volkamer, E.J. Williams, S.C. Wofsy, J. Geophys. Res. Atmos. 118(11), 5830-5866 (2013)

3. X. Liu, S.T. Cheng, H. Liu, S. Hu, D.Q. Zhang, H.S. Ning, Sensors 12(7), 9635-9665 (2012)

4. P.M. Vitousek, J.D. Aber, R.W. Howarth, G.E. Likens, P.A. Matson, D.W. Schindler, W.H. Schlesinger, D. Tilman, Ecol. Appl. 7(3), 737-750 (1997)

5. J.R. Ecker, Science 268(5211), 667-675 (1995)

6. L. Pauling, A.B. Robinson, R. Teranish, P. Cary, Proc Natl Acad Sci USA 68(10), 2374-2376 (1971)

7. S. Cristescu, S. Persijn, S. te Lintel Hekkert, F. Harren, Appl. Phys. B. 92(3), 343-349 (2008)

8. C.J. Wang, P. Sahay, Sensors 9(10), 8230-8262 (2009)

9. D.A. Rusak, B.C. Castle, B.W. Smith, J.D. Winefordner, Crit. Rev. Anal. Chem. 27(4), 257-290 (1997)

10. G.S. Engel, W.S. Drisdell, F.N. Keutsch, E.J. Moyer, J.G. Anderson, Appl. Opt. 45(36), 9221-9229 (2006)

11. D.D. Arslanov, K. Swinkels, S.M. Cristescu, F.J.M. Harren, Opt. Express 19(24), 24078-24089 (2011)

12. J. Hodgkinson, R.P. Tatam, Meas. Sci. Technol. 24(1), 012004 (2013)

13. F.J.M. Harren, J. Mandon, S.M. Cristescu, Photoacoustic spectroscopy in trace gas monitoring, in Encyclopedia of Analytical Chemistry, ed. by R.A. Meyers (Wiley, Chichester, 2012)

14. R.F. Curl, F. Capasso, C. Gmachl, A.A. Kosterev, B. McManus, R. Lewicki, M. Pusharsky, G. Wysocki, F.K. Tittel, Chem. Phys. Lett. 487(1-3), 1-18 (2010)

15. G. Wysocki, Y. Bakhirkin, S. So, F.K. Tittel, C.J. Hill, R.Q. Yang, M.P. Fraser, Appl. Opt. 46(33), 8202-8210 (2007)

16. W.W. Bewley, C.L. Canedy, C.S. Kim, M. Kim, C.D. Merritt, J. Abell, I. Vurgaftman, J.R. Meyer, Opt. Express 20(19), 2089420901 (2012) 
17. D.D. Arslanov, M. Spunei, J. Mandon, S.M. Cristescu, S.T. Persijn, F.J. Harren, Laser Photonics Rev. 7(2), 188-206 (2013)

18. F.M. Schmidt, M. Metsala, O. Vaittinen, L. Halonen, J. Breath Res. 5, 046004 (2011)

19. W. Chen, M. Metsala, O. Vaittinen, L. Halonen, J. Breath Res. 8(2), 027108 (2014)

20. C. Blumer, D. Haas, Arch. Microbiol. 173(3), 170-177 (2000)

21. W. Carroll, W. Lenney, T.S. Wang, P. Spanel, A. Alcock, D. Smith, Pediatr. Pulmonol. 39(5), 452-456 (2005)

22. K. Sanderson, L. Wescombe, S.M. Kirov, A. Champion, D.W. Reid, Eur. Respir. J. 32(2), 329-333 (2008)

23. B. Ryall, J.C. Davies, R. Wilson, A. Shoemark, H.D. Williams, Eur. Respir. J. 32(3), 740-747 (2008)

24. B. Enderby, D. Smith, W. Carroll, W. Lenney, Pediatr. Pulmonol. 44(2), 142-147 (2009)

25. F.J. Gilchrist, R.J. Bright-Thomas, A.M. Jones, D. Smith, P. Spanel, A.K. Webb, W. Lenney, J. Breath Res. 7(2), 026010 (2013)

26. D. Smith, P. Spanel, F.J. Gilchrist, W. Lenney, J. Breath Res. 7(4), 044001 (2013)

27. A.H. Neerincx, Y.A.M. Linders, L. Vermeulen, R.A. Belderbos, J. Mandon, E. van Mastrigt, M.W. Pijnenburg, J. van Ingen, J.W. Mouton, L.A.J. Kluijtmans, R.A. Wevers, F.J.M. Harren, S.M. Cristescu, P. Merkus, Eur. Respir. J. 48(2), 577-579 (2016)

28. M. Rosenfeld, R.L. Gibson, S. McNamara, J. Emerson, J.L. Burns, R. Castile, P. Hiatt, K. McCoy, C.B. Wilson, A. Inglis, A. Smith,
T.R. Martin, B.W. Ramsey, Pediatr. Pulmonol. 32(5), 356-366 (2001)

29. G. Taccetti, S. Campana, F. Festini, M. Mascherini, G. Doring, Eur. Respir. J. 26(3), 458-461 (2005)

30. A.W. Graffelman, F.E.J.A. Willemssen, H.M. Zonderland, A.K. Neven, A.C.M. Kroes, P.J. van den Broek, Br. J. Gen. Pract. 58(547), 93-97 (2008)

31. F.J. Gilchrist, S. Salamat, S. Clayton, J. Peach, J. Alexander, W. Lenney, Arch. Dis. Child. 96(3), 215-217 (2011)

32. D.D. Arslanov, M.P. Castro, N.A. Creemers, A.H. Neerincx, M. Spunei, J. Mandon, S.M. Cristescu, P. Merkus, F.J. Harren, J. Biomed. Opt. 18(10), 107002 (2013)

33. A.H. Neerincx, J. Mandon, J. van Ingen, D.D. Arslanov, J.W. Mouton, F.J.M. Harren, P.J.F.M. Merkus, S.M. Cristescu, J. Breath Res. 9(2), 027102 (2015)

34. D. Marchenko, A.H. Neerincx, J. Mandon, J. Zhang, M. Boerkamp, J. Mink, S.M. Cristescu, StL Hekkert, F.J.M. Harren, Appl. Phys. B Lasers Opt. 118(2), 275-280 (2015)

35. P. Werle, R. Mucke, F. Slemr, Appl. Phys. B Photophys. Laser Chem. 57(2), 131-139 (1993)

36. C. Hill, I.E. Gordon, R.V. Kochanov, L. Barrett, J.S. Wilzewski, L.S. Rothman, J. Quant. Spectrosc. Radiat. Transf. 177, 4-14 (2016) 